\title{
Is there a real need for a short- stay unit in Al Ain, United Arab Emirates?
}

Tewfik K. Daradkeh, Omer E. F. El-Rufaie, Yahia Younis and Rafia Ghubash

\begin{abstract}
This study explores the rationale and need for a short-stay poychiatilic unit of A Ain (Uniled Arab Emirates) district hoeplital. The paper describes the demographic and diagnostic characteristics of patients with brief admissions over $40 \%$ - of all psychiatilic admisstons - most of whom have neurotic, stress-related and adjustment disorders. Only $12 \%$ of patients were severely discbled and in about half the patients, anxiolytic or no medications were prescribed. Sionilicant reduction of distress was achloved by brief admission. In current circumstances, we believe that the short-stay unit might be the best avallable and least costly option.
\end{abstract}

The sparse data available indicate that less severely ill patients treated in short-stay units fare as well as or better than those managed on conventional in-patient wards (Herz et al, 1977; Martin et al, 1985; Gordon \& Breakey, 1983; Schwartz \& Vallance, 1987). Short-stay patients spend fewer days in hospital, which reduces financial cost and increases bed avallability (Schwartz \& Vallance, 1987). These benefits are not at the expense of increased rates of readmission (Hertz et al, 1977; Martin et al, 1985; Gordon \& Breakey, 1983).

\section{Background and rationale}

From the inception of psychiatric services in $A$ Ain, in the early 1970s, services to mentally ill persons were delivered through an out-patient general hospital psychiatric unit and a joint medico-psychiatric in-patient unit. The arrival of the university department of psychiatry in 1990 was an impetus for the expansion of psychiatric services in Al Ain. Psychiatric services were extended into primary health care, new medical, paramedical and nursing staff were recruited and a new psychiatric unit with more bed capacity than the old one was established in July 1993. Plans for rehabilitative and community oriented psychiatry were put forward. All this opened the door for postgraduate training programmes in psychiatry and the newly established service was granted a provisional recogni- tion as a postgraduate training centre by the Arab Board, the highest professional medical body in the Arab world. A computerised psychiatric register was established which records details of all in-patient episodes.

Unfortunately, some of our plans came to a halt as the building of the new unit began to crack and was attributed to land sliding. Portions with the most marked cracks were closed, leaving us with a small functional area. We have been promised by the health authorities that a new unit will be built in the near future but have to cope with what we have at the present time. This situation prompted us to look into the literature on how to cope with a smaller inpatient unit. Short-stay wards or units were reported to partially absorb pressure on traditional units and could be the final path patients could get to. We therefore intended to find the characteristics of patients admitted to our unit with less than one week of hospitalisation and whether they would justify the establishment of a short-stay unit.

\section{The study}

Records of patients with first ever admissions of less than one week duration to the unit from November 1993 to August 1995 were retrieved from the computerised psychiatric register. The computerised database includes details on demographics, diagnostic categories (ICD-10; World Health Organization, 1992), clinical aspects, treatment and degree of associated dysfunction or disabilities. Tabulation of patients by gender, nationality, employment status, disabilities, ICD-10 diagnosis, medications received, 'receipt of ECT' and combination of drugs were carried out. To test the efficacy of short hospitalisation, Wilcoxon matched tests were performed to test the significance of changes in dysfunction or disability on admission and on discharge. 


\section{Findings}

One hundred and seventy patients were identified for the study. They constituted over $40 \%$ of all admissions. There were 85 male and 85 female patients. Their mean age was 30.12 with a range from 13-79 years. The mean length of stay was 2.9 days. The distribution of patients by disability was: $16 \%$ with minimum or no disability, $32 \%$ with mild disability, $40 \%$ with moderated disability and $12 \%$ with severe disability. The most common diagnoses were neurotic, stress-related, adjustment and dissociative disorders (44.7\%), followed by mood disorders (18.4\%). About 5\% had a diagnosis of schizophrenia and related disorders. Organic mental disorders and substance use disorder each accounted for about $5 \%$ of patients. Two patients were given ECT. Over half of patients were prescribed no medications or anxiolytics alone, $24 \%$ and $23 \%$ of patients were prescribed antidepressants and neuroleptics respectively.

About $9 \%$ of patients were unemployed and the rest were employed, students or housewives. Nearly $79 \%$ were discharged to the out-patient clinic, $4 \%$ were transferred to medical or surgical facilities within the same hospital, $6.5 \%$ were finally discharged from psychiatric services, because there was no need for them to attend psychiatric services, and the rest were referred to psychiatric and non-psychiatric medical facilities outside Al Ain medical district. At the 5\% level, significant reduction in dysfunction was achieved by brief admission. Table 1 summarises the details of all patients.

\section{Comment}

Our computerised register reveals that patients with brief admission constituted over $40 \%$ of patients admitted. The significant difference in disability at admission and discharge indicates the usefulness of brief admissions. Although the majority of patients were diagnosed as having neurotic, stress-related and somatoform disorders, $25 \%$ were assigned a diagnosis of mood or schizophrenic disorders. The broad spectrum of diagnostic status of patients with short admissions indicates that less severely and severely ill patients also benefit from short admissions. Our findings accord with those of Mok \& Walter (1995) who reported the following diagnostic status of patients with short admissions: adjustment disorder in $46 \%$, followed by substance abuse $(30 \%)$, bipolar disorder $(8 \%)$, dysthymia (7\%), schizophrenia (6\%), major depression (5\%), and schizophreniform disorder (5\%). If a shortstay unit existed, $40 \%$ of all patients requiring hospitalisation would have been admitted there rather than to a conventional in-patient psychiatric unit. A literature review indicates that short-
Table 1. Dlagnoses and treatments of the sample

\begin{tabular}{|c|c|c|}
\hline & $n$ & \% \\
\hline \multicolumn{3}{|l|}{ Diognostlic categories } \\
\hline $\begin{array}{l}\text { Acute and transient psychotic } \\
\text { disorders (F23) }\end{array}$ & 6 & 3.5 \\
\hline \multicolumn{3}{|l|}{$\begin{array}{l}\text { due to psychoactive substance } \\
\text { use (FII-F19) }\end{array}$} \\
\hline $\begin{array}{l}\text { Reaction to severe stress and } \\
\text { adjustment disorders (F43) }\end{array}$ & 35 & 20.6 \\
\hline $\begin{array}{l}\text { Mental and behavioural disorders } \\
\text { due to alcohol use (F10) }\end{array}$ & 1 & 1.8 \\
\hline $\begin{array}{l}\text { Neurotic disorders (F40-F4l) } \\
\text { Bipolar dlsorders (F31) }\end{array}$ & $\begin{array}{r}10 \\
4\end{array}$ & $\begin{array}{l}5.9 \\
2.4\end{array}$ \\
\hline Dissociative disorders (F44) & 30 & 17.6 \\
\hline Depressive eplsodes (F32) & 19 & 11.2 \\
\hline Manic (hypomanic) eplsodes (F30) & 3 & 1.8 \\
\hline Obsessive-compulsive disorder (F42) & 1 & 0.6 \\
\hline Organic mental disorders (FOO-FO9) & 7 & 4.1 \\
\hline Paranold disorders (F22) & 2 & 1.2 \\
\hline Persistent mood disorders (F34) & $i$ & 0.6 \\
\hline Personalty disorders (F60-F69) & 7 & 4.1 \\
\hline Recurrent depresstve disorders (F33) & 4 & 2.4 \\
\hline Schizophrenla (F20) & 7 & 4.1 \\
\hline Somatoform disorders (F45) & 2 & 1.2 \\
\hline Others & 21 & 12.4 \\
\hline \multicolumn{3}{|l|}{ Discability on admisaton } \\
\hline Minimum & 27 & 15.9 \\
\hline Mild & 55 & 32.4 \\
\hline Moderate & 68 & 40 \\
\hline Severe & 20 & 11.8 \\
\hline \multicolumn{3}{|l|}{ Electroconvulatve thercepy } \\
\hline No & 168 & 98.8 \\
\hline Yes & 2 & 1.2 \\
\hline \multicolumn{3}{|l|}{ Type of medication } \\
\hline Anxiolytic alone or no medications & 91 & 53.5 \\
\hline $\begin{array}{l}\text { Antidepressants with and without } \\
\text { anxiolytics }\end{array}$ & 40 & 23.5 \\
\hline $\begin{array}{l}\text { Neuroleptics with and without } \\
\text { other drugs }\end{array}$ & 39 & 22.9 \\
\hline \multicolumn{3}{|l|}{ Number of drugs recelved } \\
\hline No drugs & 60 & 35.3 \\
\hline One drug & 60 & 35.3 \\
\hline Two drugs & 38 & 22.3 \\
\hline > two drugs & 3 & 1.8 \\
\hline Unknown & 9 & 5.3 \\
\hline Total & 170 & 100 \\
\hline
\end{tabular}

stay units increase bed availability and reduce cost (Herz et al, 1977; Martin et al, 1985; Gordon \& Breakey, 1983; Mok \& Walter, 1995). Our findings support this observation. One interesting finding is that patients with brief admissions are less likely to receive polypharmacy and as a result are less likely to develop adverse sideeffects. 


\section{Conclusion}

The high proportion of patients with brief admission justifies the establishment of shortstay units. Such units could accommodate not only stress-related minor disorders but those with moderate and severe forms of illnesses. Brief admissions of patients with severe illnesses renders such patients more amenable to outpatient care. We believe that a short-stay unit reduces pressure on the remaining part of the inpatient unit. Staff of the existing unit can run the proposed unit and as a result the health authorities will be more willing to agree an immediate plan of action. The limitations of this study are the lack of information about the symptomatic and follow-up outcomes of such patients.

\section{References}

GORDON, T. \& BREAKEY, W. R. (1983) A compartson of the outcomes of short- and standard-stay patients at oneyear follow up. Hospital and Community Psychiatry, 34. 1054-1056.
HERZ, M. ENDICOTT, J. \& SPTZZR, R. L. (1977) Brief hospitalization: a two-year follow-up. American Joumal of Psychiatry, 134, 502-507.

Martin, B. A., Cermignani, P. \& Vorneskos, G. (1985) A short-stay ward in a psychiatric hospital: effect on hospital caseload. British Journal of Psychiatry, 147. 82-87.

MOK H. \& WALTER C. (1995) Brief psychiatric hospitalization: preliminary experience with an urban short-stay unit. Canadian Jownal of Psychtatry, 7, 415417.

SCHWARZ, C. \& VALLANCE, M. (1987) Length of stay. Hospital and Community Psychiatry, 38, 201.

WORLD HEALTH ORGANIZATION (1992) The Tenth Revision of the International Classification of Diseases and Related Health Problems (ICD-10). Geneva: WHO.

Tewfik K. Daradkeh, Associate Professor; Omer E. F. El-Rufaie, Associate Professor; Yahia Younis, Consultant Psychiatrist; and Rafia Ghubash, Assistant Professor, Department of Psychiatry and Behavioural Sciences, Faculty of Medicine and Health Sciences, UAE University, Al Ain, PO Box 17666, United Arab Emirates

*Correspondence 